\title{
Chlamydia Trachomatis Peritonitis: Report of a Patient Presenting Spontaneous Regression of Ascites
}

\author{
Nobuyoshi Yanagisawa, Hitoshi Tomiyasu, Tetsuya Hada, Nariaki Kure, Yumiko Kobayashi, \\ Tetsurou Katamoto, Hitoshi Sugaya* and Takashi Harada*
}

\begin{abstract}
A 36-year-old Japanese woman complained of right hypochondralgia followed by ascites. Paracentesis showed a turbid, straw-colored sterile exudate. Computed tomography and magnetic resonance imaging of the abdomen revealed a left periuteric mass and ascites. The mass and ascites spontaneously regressed within a month with no specific treatment. Later, after the patient had been discharged from hospital, immunofluorescence antibody titers for Chlamydia trachomatis were successfully determined using stored ascitic fluid and serum. Though the number of cases of Chlamydia trachomatis peritonitis has increased, few cases with ascites have been reported, and spontaneous regression of the ascites is also rare.

(Internal Medicine 31: 835-839, 1992)
\end{abstract}

Key words: PID, Chlamydia trachomatis, Fitz-Hugh-Curtis syndrome

\section{Introduction}

Infections caused by Chlamydia trachomatis (C. trachomatis) are known to occur in any organ, such as eyes, lungs, colon, lymph nodes, peritoneal cavity or genitourinary systems. In recent years, the increased sexual activity of younger women has raised the frequency of sexually transmitted diseases (STD) caused by this organism. Reports of pelvic inflammatory disease (PID) and intra-abdominal inflammatory disease $(1-5)$ caused by this organisms, which were not common earlier, have been increasing in number. Few cases of ascitic peritonitis due to this organism have been reported. Here, we report a case of peritonitis in whom the ascites regressed spontaneously.

\section{Case Report}

A 36-year-old Japanese office woman presented on May 7, 1990 with symptoms of right hypochondralgia. Her past medical history was not remarkable; there was no familial disease and she had not received any blood transfusion. She had a clear vaginal discharge after her last menstruation early in April. Then the discharge increased and became off-colored; she felt sharp pain in the right inguinal area. She had not had sexual inter- course in previous last five months. She underwent an abdominal ultrasonography in a gynecological clinic, and a cervical polyp was found. Although it was recommended that she have it removed, she did not consent to any surgical treatment. Pain in the right inguinal area continued and migrated to the right hypochondrial region. When she visited our hospital, she underwent another abdominal ultrasonography, but no remarkable changes were found in the abdomen. Her symptoms improved after oral administration of antiphlogistics (Tiaprofenic acid, $300 \mathrm{mg} /$ day). On May 28 in another clinic, she underwent transvaginal resection of the cervical polyp. She revisited our hospital on May 20 complaining of a feeling of fullness in the lower part of the abdomen and $3 \mathrm{~kg}$ body weight loss in the last 6 weeks.

Physical examination revealed a well nourished afebrile woman with mild anemia and a slight tenderness in the right hypochondrial region and ascites. There were no other remarkable findings and no findings suggestive of liver disease such as spider angioma, engorged vein on the abdominal wall or palmar erythema.

Laboratory data are shown in Table 1 . Slight anemia, positive C-reactive protein (CRP), mild leukocytosis and a moderate increase in erythrocyte sedimentation rate (ESR) were the only abnormalities noted, and other data were normal, including the liver blood chemistries

From the Division of Gastroenterology, JR Tokyo General Hospital, Tokyo and *Second Department of Internal Medicine, Dokkyo, University School of Medicine, Tochigi

Received for publication July 19, 1991; Accepted for publication March 25, 1992

Reprint requests should be addressed to Dr. Nobuyoshi Yanagisawa, the Second Department of Internal Medicine, Dokkyo University School of Medicine, 880 Kitakobayashi, Mibu, Shimotsugagun, Tochigi 321-02, Japan 
Table 1. Laboratory Data (May 15 1990)

\begin{tabular}{|c|c|c|c|}
\hline \multicolumn{2}{|c|}{ Peripheral blood } & \multicolumn{2}{|l|}{ Serological test } \\
\hline $\mathrm{RBC}$ & $3.09 \times 10^{6} / \mathrm{mm}^{3}$ & $\mathrm{HBs} \mathrm{Ag}$ & $(-)$ \\
\hline $\mathrm{Ht}$ & $28.8 \%$ & anti-HBs & $(-)$ \\
\hline $\mathrm{Hb}$ & $9.6 \mathrm{~g} / \mathrm{dl}$ & STS & $(-)$ \\
\hline WBC & $8900 / \mathrm{mm}^{3}$ & & \\
\hline stab & $8 \%$ & LE Cell & $(-)$ \\
\hline seg & $67 \%$ & LE Test & $(-)$ \\
\hline lym & $12 \%$ & ANA & $(-)$ \\
\hline Plt & $48.2 \times 10^{4} / \mathrm{mm}^{3}$ & Anti-DNA & $(-)$ \\
\hline ESR & $90 \mathrm{~mm} / 1 \mathrm{~h}$ & $\mathrm{CH}_{3}$ & $34 \mathrm{U} / \mathrm{ml}$ \\
\hline Biochemistry & & Tumor marker & \\
\hline $\mathrm{TP}$ & $7.6 \mathrm{~g} / \mathrm{dl}$ & CEA & $1.7 \mathrm{ng} / \mathrm{ml}$ \\
\hline Alb & $4.1 \mathrm{~g} / \mathrm{dl}$ & CA19-9 & $5>\mathrm{U} / \mathrm{ml}$ \\
\hline $\mathrm{A} / \mathrm{G}$ & 1.17 & CA125 & $321 \mathrm{U} / \mathrm{ml}$ \\
\hline BUN & $15.2 \mathrm{mg} / \mathrm{dl}$ & SLX & $32.3 \mathrm{U} / \mathrm{ml}$ \\
\hline $\mathrm{Cr}$ & $0.7 \mathrm{mg} / \mathrm{dl}$ & DUPAN-2 & $29 \mathrm{U} / \mathrm{ml}$ \\
\hline T-Bil & $0.3 \mathrm{mg} / \mathrm{dl}$ & $\mathrm{ADA}$ & $10 \mathrm{U} / 1$ \\
\hline GOT & $13 \mathrm{KU}$ & & \\
\hline GPT & $11 \mathrm{KU}$ & Hormonal test & \\
\hline Alp & $73 \cup / 1$ & $\mathrm{~T} 3$ & $9.8 \mathrm{ng} / \mathrm{dl}$ \\
\hline$\gamma$-GTP & $6 \mathrm{U} / 1$ & $\mathrm{~T} 4$ & $8.6 \mathrm{ng} / \mathrm{dl}$ \\
\hline Ch-E & $3368 \mathrm{IU} / 1$ & TSH & $1.96 \mathrm{ng} / \mathrm{dl}$ \\
\hline CRP & $2.8 \mathrm{mg} / \mathrm{dl}$ & & \\
\hline
\end{tabular}

and renal function tests. The CA 125 value $(321 \mathrm{U} / \mathrm{ml})$ was slightly elevated. PPD skin test was moderately positive $(8 \times 5 / 24 \times 16 \mathrm{~mm})$. Computed tomography (CT) of the abdomen revealed moderate ascites and a mass in the left side of the uterus which showed isodensity compared to uterus density (Fig. 1). The magnetic resonance image (MRI) of the mass revealed an area of slightly low signal intensity on the T1-weighted image and an area of high signal intensity on the T2-weighted image (Fig. 2). X-ray examination of the upper gastrointestinal tract and barium enema examination were not remarkable. Paracentesis performed on June 13 showed a turbid, straw-colored exudate with a specific gravity of 1.025 and a high protein concentration $(8.2 \mathrm{~g} / \mathrm{dl}$; albumin $32.9 \%$, gamma-globulin $50.6 \%$ ). Differentiation of the

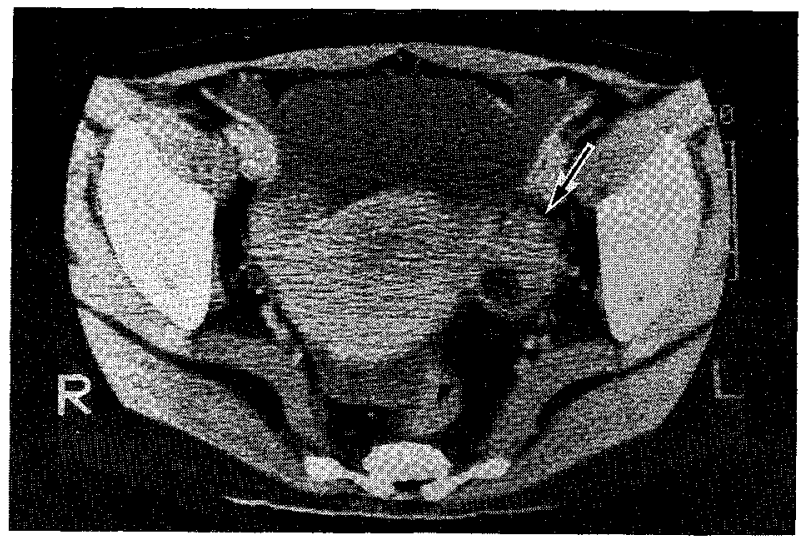

Fig. 1. Computed tomography reveals moderate ascites and a mass in the left side of the utcrus (arrow) which showed isodensity compared to uterus density.

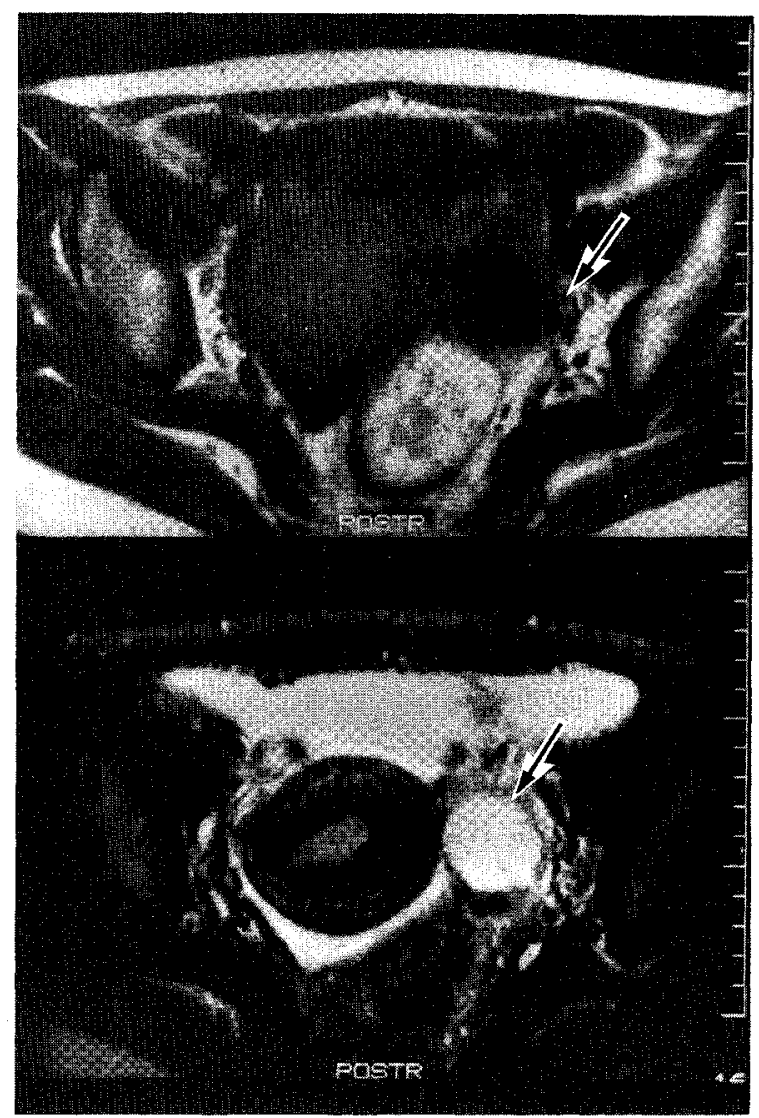

Fig. 2. Magnetic resonance imaging reveals moderate ascites and periuteric mass, the latter is detected by the area of slightly low signal intensity on the T1-weighted image (upper arrow), and by the area of high signal intensity in $\mathrm{T} 2$-weighted imagc (lower arrow).

ascites cells showed $30 \%$ granulocytes, $69 \%$ lymphocytes and $1 \%$ eosinophils. Culture of ascites was negative for bacteria including tuberculosis. Cytology indicated class IIIb, but repeat cytology was not available due to spontaneous regression of the ascites. Cefoteram pivoxil (CFTM-PI), a dose of $300 \mathrm{mg}$ per day was administered per os for three days following the paracentesis. On June 19 , ascites reached the maximum volume, thereafter it began to decrease gradually. On July 4 , the ascites was no longer detectable on ultrasonogram.

The clinical course of this patient is shown in Fig. 3. Although the CRP and WBC count returned to normal values by July 4 , the increased serum total proteins, decreased $A / G$ ratio, elevated ESR and decreased hemoglobin concentration persisted. Serum CA 125 value decreased to $76 \mathrm{U} / \mathrm{ml}$ after regression of the ascites. On July 12 , the periuteric mass was undetectable on MRI which was concomitant with the regression of ascites. She was discharged from our hospital on July 21 .

As retrospective peritonitis due to inflammatory disease of the periuteric area was suspected from these clinical findings, the stored serum and ascites (frozen at $-80^{\circ} \mathrm{C}$ ) were analyzed for antibody titers for C. tracho- 


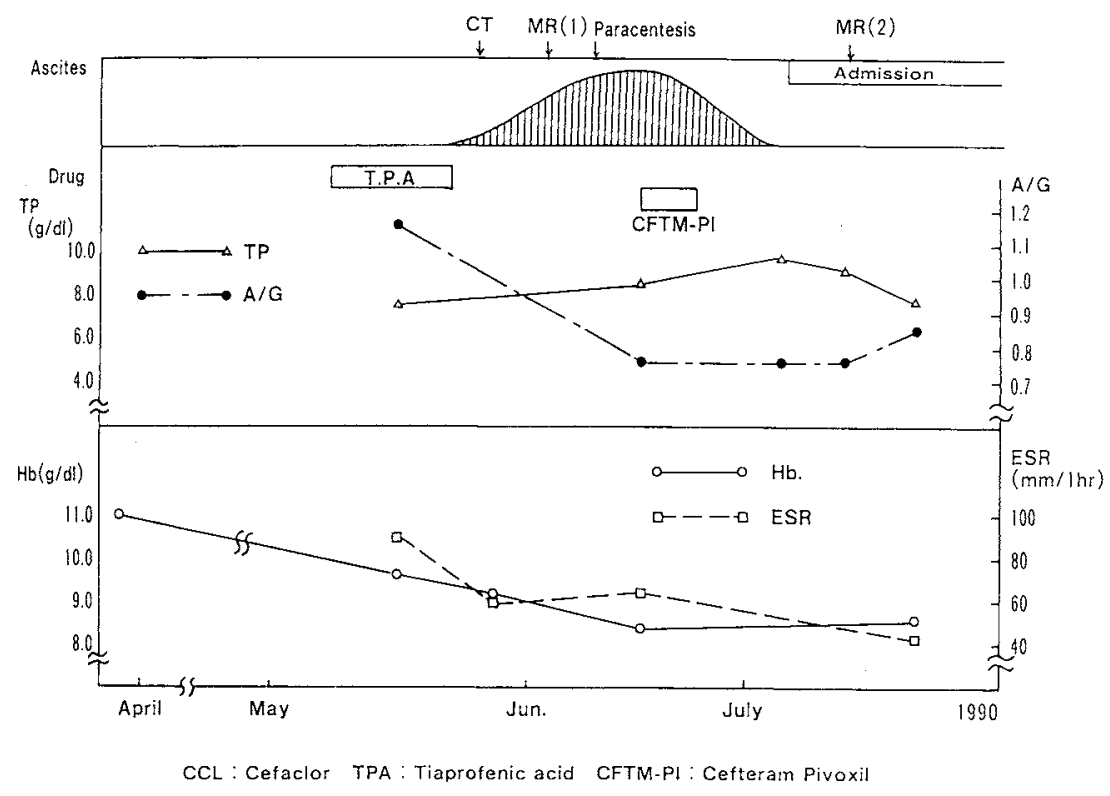

Fig. 3. Clinical course

Table 2. Antibody Titer

1) Chlamydia trachomatis

\begin{tabular}{llll}
\hline \multirow{2}{*}{ Serum } & IF & IgM & $1 \cdot 64$ \\
\cline { 2 - 4 } & & IgG & $1: 4096$ \\
\cline { 2 - 4 } Micro IF & Type & F,G \\
\hline \multirow{2}{*}{ Ascites } & IF & IgM & $1: 512$ \\
\cline { 3 - 4 } & & IgG & $1: 8192$ \\
\hline
\end{tabular}

2) Neisseria gonorrhea

\begin{tabular}{llll}
\hline \multirow{2}{*}{ Serum } & PHA & & $1: 4$ \\
\cline { 2 - 4 } & ELISA & IgM & 10.5 \\
\cline { 3 - 4 } & & $\operatorname{IgG}$ & 12.3 \\
\hline
\end{tabular}

matis and Neisseria gonorrhea (N. gonorrhea). The immunofluorescent antibody titer for $\mathrm{C}$. trachomatis was 1:64 for $\operatorname{IgM}$, and 1:4096 for $\mathrm{IgG}$ in serum, and 1:512 for IgM and 1:8192 for IgG in ascites: the antibody titer for $\mathrm{N}$. gonorrhea was negative (Table 2). Thus, this patient was diagnosed as peritonitis due to $\mathrm{C}$. trachomatis. Erythromycin (EM) was administered after her discharge from hospital, however we could not carry out a followup study because she did not visit our hospital thereafter.

\section{Discussion}

The diagnosis of C. trachomatis infection is generally based on the presence of IgM or IgG antibody to C. trachomatis in the serum determined by immunofluorescent techniques. A recent study (6) demonstrated that the diagnosis can be also made by a staining method or culture of $\mathrm{C}$. trachomatis from an adhesion in the abdominal cavity obtained during surgery or laparoscopy, but few positive cultures for ascites have been reported (7). As laparoscopy was not performed in the present case, the antibody titers for $\mathrm{C}$. trachomatis in the ascitic fluid were analyzed in attempt to identify the causative organism for the intra-abdominal infection. To our knowledge there is no report on the determination of antibody titers for $\mathrm{C}$. trachomatis in ascitic fluid. As specific antibody titers can be determined in serum, secretions, tears, semen and cervical mucus (8), we thought that the determination of the antibody titers in the ascitic fluid might contribute to the diagnosis in $\mathrm{C}$. trachomatis infection. It is likely that the high titers of $\operatorname{IgM}$ and IgG antibodies for $\mathrm{C}$. trachomatis in the present case reflect intra-abdominal infection with this organism. Moreover higher titers of the antibody in the ascitic fluid may be suggestive of $\mathrm{C}$. trachomatis peritonitis.

Since the first report of Chlamydial infection associated with ascites in 6 cases by Müllar-Schoop et al (9) in 1978, few similar cases have been reported. As shown in Table 4 , in 9 cases from 7 reports $(7,10-15), 6$ were caused by infection of $\mathrm{C}$. trachomatis. Exudative ascites with a high protein content is a common finding and the major cell component are lymphocytes which are present in $54 \%$ to $94 \%$, regardless of the number of leukocytes. Since similar findings were seen in the present case, we suppose that the mechanism for the development of ascites in this patient was similar to that in the 9 cases in the literatures $(7,10-15)$. The main symptom of our patient was pain in the right inguinal region that 
Table 3. Main features of cases of $\mathrm{C}$. trachomatis with ascites

\begin{tabular}{|c|c|c|c|c|c|c|c|c|c|c|c|}
\hline \multirow{2}{*}{ Author } & \multirow{2}{*}{ Age } & \multicolumn{2}{|c|}{ C. trachomatis $\mathrm{Ab}$} & \multicolumn{5}{|c|}{ Ascites } & \multirow{2}{*}{ Cervix culture } & \multirow{2}{*}{ Treatment } & \multirow{2}{*}{ Diagnosis } \\
\hline & & $\operatorname{IgM}$ & $\operatorname{Ig} G$ & Protein $(g / 1)$ & WBC s & Lymph & h count & Culture & & & \\
\hline $\begin{array}{l}\text { Lannigan (10) } \\
\quad(1980)\end{array}$ & 21 & $1: 64$ & $1: 4096$ & 74 & 1600 & \multicolumn{2}{|c|}{$\begin{array}{l}\text { Many mononuclear } \\
\text { ccll }\end{array}$} & negative & negative & $\mathrm{TC}$ & $S$ \\
\hline $\begin{array}{l}\text { Marbet (7) } \\
\quad(1986)\end{array}$ & 26 & - & - & - & - & & - & positive & positive & DOXY & P.S \\
\hline $\begin{array}{l}\text { Haight (12) } \\
\text { (1988) }\end{array}$ & 26 & - & $1: 1024$ & 89 & 10500 & 5670 & $(54 \%)$ & nd & nd & TC & $\mathrm{P}$ \\
\hline $\begin{array}{l}\text { Labat-Labour (13) } \\
\text {-dette (1989) }\end{array}$ & 19 & $1: 128$ & $1: 6000$ & 72 & 1410 & 1325 & $(94 \%)$ & negative & nw & DOXY & P.S \\
\hline $\begin{array}{l}\text { Guagenti (14) } \\
\text { (1989) }\end{array}$ & 23 & \multicolumn{2}{|c|}{$\begin{array}{c}1: 20 \\
\text { (ERISA) }\end{array}$} & 92 & 4700 & 2867 & $(61 \%)$ & nd & nw & DOXY & P.S \\
\hline
\end{tabular}

C. trachomatis Ab: Chlamydia trachomatis Antibody (Immunofluorescence) nd: not done, nw: not written, P: perihepatitis, S: salpingitis

then migrated to the right hypochondrial region, which might have occurred concomitant with the spread of the inflammatory process within the abdominal cavity and perihepatitis (Fitz-Hugh-Curtis syndrome).

Administration of EM, tetracycline (TC) or doxycycline (DOXY) is the generally accepted treatment for C. trachomatis infection; in 8 of the reported 9 cases (7, 10-15) ascites decreased after TC treatment. The remaining postoperative patient (11) improved after administration of ampicillin (ABPC) although the spectrum of action of ABPC does not include C. trachomatis. Furthermore, Müller-Schoop et al (9) reported that 4 of 9 patients with $C$. trachomatis peritonitis improved $1-2$ weeks after the administration of $\mathrm{ABPC}$, but there was no description of ascites. In the present case, ascites developed after short-term administration of CFTM-CI, but regressed without administration of EM or DOXY; these were not given to the patient because the diagnosis of $\mathrm{C}$. trachomatis infection was made retrospectively after recovery. From these facts, we suppose that ascites associated with $\mathrm{C}$. trachomatis infection may have been a self-limiting symptom, but the administration of TC or EM would benefit the patient, because anemia and signs of inflammation in blood tests were persistent. The frequency of $\mathrm{C}$. trachomatis infection of the genitourinary tract has been increasing in recent years with concomitant increase in intra-abdominal infection by this organism. Therefore the possibility of $\mathrm{C}$. trachomatis peritonitis should be considered when a patient presents with abdominal pain of unknown origin especially in sexually active women.

Acknowledgments: We would like to express our thanks to Dr. E. Kita (Nara Prefectural University School of Medicine, Depart- ment of Bacteriology) for his advice regarding the bacteriological examination.

\section{References}

1) Curtis AH. A case of adhesions in the right upper quadrant. $\mathbf{J}$ Am Med Assoc 94: 1221, 1930.

2) Fitz-Hugh $\mathrm{T} \mathrm{Jr}$. Acute gonococcic peritonitis of the right upper quadrant in women. J Am Med Assoc 102: 2094, 1934.

3) Yamashita $Y$, Kajimura K, Kajiyama $T$, et al. Three suspected cases of perihepatitis caused by Chlamydia tracomatis infection (Fitz-Hugh-Curtis syndrome). Jpn J Gastroenterol 83: 2612, 1986.

4) McCormick M, Del Castillo J, Berk RS, et al. An atypical presentation of Fitz-Hugh-Curtis syndrome. J Emerg Med 8: 55, 1990.

5) Katzman DK, Friedman IM, McDonald CA, et al. Chlamydia tracomatis Fitz-Hugh-Curtis syndrome without salpingitis in female adolescents. Am J Dis Child 142: 996, 1988.

6) Wolner HP, Svenson L, Westron L. Isolation of Chlamydia tracomatis from the liver capsule in Fitz-Hugh-Curtis syndrome. N Engl J Med 113: 306, 1982.

7) Marbet UA, Stalder GA, Vogtlin J, et al. Diffuse peritonitis and chronic ascites due to infection with Chlamydia tracomatis in patients without liver disease: new presentation of Fitz-HughCurtis syndrome. Br Med J 293: 5, 1986.

8) Wang SP, Grayston JT. Microimmunofluoresence Antibody Responses in Chlamydia Tracomatis Infection, A Review. in: Chlanydial Infection, Mardh PA, Holmes KK, Oriel JD, Piot P, Schachter J, Eds. Elsevier Biomedical Press, Amsterdam, 1982, p. 301.

9) Müller-Schoop JW, Wang SP, Munzinger J, et al. Chlamydia tracomatis as possible cause of peritonitis and perihepatitis in young women. Br Med J 22: 1022, 1978.

10) Lannigan R, Hardy G, Tanton R, et al. Chlamydia tracomatis peritonitis and ascites following appendectomy. Can Med Assoc J 123: 295, 1980.

11) Punnonen R, Terho P, Klemi P. Chlamydia pelvic inflammatory disease with ascites. Fertil Steril 37: 270, 1982.

12) Haight JB, Ockner SA. Chlamydia tracomatis perihepatitis with ascites. Am J Gastroenterol 83: 323, 1988. 


\section{Chlamydia Trachomatis Peritonitis}

13) Labat-Labourdette J, Silvain C, Ducroz B, et al. Ascite isólee revelatrice dúne infection a Chlamydia tracomatis. Gastroenterol Clin Biol 13: 634, 1989.

14) Guagenti RC, Berman AL, Cohen NN. Chlamydial ascites.
Dig Dis Sci 34: 139, 1989.

15) Votte-Lambert A, Joly JP, Becuwe C, et al. Chlamydia tracomatis peritonitis: Another cause of protein-rich lymphocytic ascites. J Clin Gastroenterol 12: 341, 1990. 